\title{
18 English as a lingua franca and educational impact in Asia
}

\section{Andy Kirkpatrick}

\begin{abstract}
This chapter will begin with a brief historical review of languages which have operated as lingua francas across East and Southeast Asia. It will then review the development of English in selected Asian countries and its role in those countries today. It will be argued that the role of English in Asia has now extended beyond operating at intranational level, as evidenced by the existence of established varieties of English such as Malaysian and Filipino, to becoming an interregional lingua franca. That is to say, a major Asian role of English is as a medium of interregional communication for Asian multilinguals for whom English is an additional language. Evidence for this comes, for example, from the legislation of English as the sole working language of the ten countries which make up the Association of Southeast Asian Nations (ASEAN). Drawing on research based on a study of which languages are currently being used as languages of education in schools' curricula in selected Asian countries, using the Philippines and Indonesia as case studies, the chapter will consider the educational impacts of the role of English as a lingua franca in Asia. This section of the chapter will include tentative predictions for the respective roles of English and Asian languages. The chapter will conclude with suggestions for a 'Communicating-with Asia' skill-set which Europeans might find useful.
\end{abstract}

\subsection{Introduction - regional lingua francas}

The Association of Southeast Asian Nations (ASEAN) was formally established with the Bangkok Declaration of 8 August 1967. The date was no accident, as ' 8 ' is a lucky number in many Asian cultures and the double eighth at least doubly so. Five countries comprised the original grouping, namely Indonesia, Malaysia, the Philippines, Singapore and Thailand. Language - in particular which language(s) might be used as official or working languages was not addressed. Delegates reported that they just assumed that the working language would be English (Okudaira 1999). This tacit and assumed adoption 
of English must seem remarkable to Europeans who have lived through the genesis and growth of the European Community with its automatic adoption of national languages as official and working languages. It is even more remarkable that ASEAN adopted an English only policy when Malay was an obvious choice to be at least a co-official language. It was an obvious choice because it is both an official and the national language of Singapore and the national language of Malaysia and Indonesia (although Bahasa Indonesia shows some variation from Bahasa Melayu). Varieties of Malay are also spoken in the southern parts of the Philippines and Thailand. Hence, Malay had a significant presence in each of the five founding member states of ASEAN. Importantly, Malay has had a long history of being a regional lingua franca. Indeed it is currently one of those languages, along with English, Persian, Swahili and Urdu, which has more lingua franca speakers than mother tongue speakers (Ostler 2010: 227). Its long history as a lingua franca starts at the beginning of the first millennium, when Chinese travelers to the Indonesian Archipelago called the lingua franca in use there Kw'enlun. 'There is no doubt that the Kw'enlun of the early travelers was a form of Malay' (Alisjahbana 1974: 392). While a form of Malay acted as a lingua franca for several centuries, the first glossary we have of the language was the one recorded in 1521 by Pigafetta, a member of Magellan's party in his voyage around the world. In 1614, a Dutch navigator, Jan Huygen van Linschoten, wrote that Malay was both widely spoken and the most prestigious language of the Orient (Alisjahbana 1974: 363). It was used as a lingua franca by the Dutch during the period of their 300-year (1650-1950) rule over Indonesia (Ostler 2010). To a certain extent, this backfired, as it was adopted as the lingua franca by groups seeking independence, 'the language of unity against the Dutch' (Bernard 2003: 273).

This was a strong reason why it then became adopted as the national language of an independent Indonesia, although it was only spoken by a very small minority of the population. In fact, the low number of native speakers also worked in its favour in its adoption as the national language. The largest Indonesian language, with some 75 million speakers, is Javanese (Montolalu and Suryadinata 2007). But, as the Javanese were already the most powerful ethnic group in Indonesia, there was reluctance at further advantaging them by making their language the national language. Other reasons for caution at the adoption of Javanese is that Javanese is a highly hierarchical society and these hierarchies are linguistically reflected in complex ways in the language. A further reason for the adoption of Malay as the national language of Indonesia is that it is relatively easy to learn (Ostler 2005). Its adoption as Indonesia's national language - now called Bahasa Indonesia - means, of course that it has become the lingua franca of Indonesia, a richly diverse and multilingual nation where some 700 languages are spoken by several hundred different ethnic groups (Lewis et al. 2014). 
It is this long history and current use of Malay as a regional lingua franca that makes it surprising that Malay was not suggested as a working language of the original ASEAN grouping. In the years following the founding of ASEAN in 1967, five more countries have joined at various times so that Brunei, Cambodia, Laos, Myanmar and Vietnam are now all members. Vietnam, in preparation for membership in 1995, asked whether French could also be adopted as a working language of ASEAN, but this was summarily turned down (Okudaira 1999). A request for Malay was tabled in 1997, but was not taken up. In 2009, the ASEAN Charter was signed. Article 34 of the Charter, 'Working Language of ASEAN', simply reads, 'The working language of ASEAN shall be English', thus making official forty years of unofficial practice.

We have seen how English has become the official and sole working language of ASEAN and how Malay, although denied an official role within ASEAN, has become the national language - and thus the national lingua franca - of Indonesia. The nations of ASEAN have likewise promoted national languages in an effort to encourage a sense of national identity and these have become national if not regional lingua francas. For example, the Philippines, a country with around 170 languages (Dekker and Young 2005) has established Filipino as the national language. The very name of the national language has itself been a creation, as, to some extent, has the language itself. In 1959, it was decreed that Pilipino would be the name given to the national language. This was to distinguish it from Tagalog, the language spoken in and around Manila, the national capital, although, it was, in effect, Tagalog. The 1973 Constitution stated that the national language 'needed to be formed from all existing Philippine languages' (Gonzalez 1996: 328). Given the number of Filipino languages, that was clearly an impossible task. The 1987 Constitution rechristened the national language from Pilipino to Filipino, significant in that there is no $[\mathrm{F}]$ sound in Tagalog, and this was a way of trying to indicate that Filipino was not Tagalog 'with ethnic extras' (Kirkpatrick 2010a: 37). The year 1987 also saw the creation of the National Language Institute (Komyson sa Wikang Filipino), one of whose task's was to develop Filipino based on existing languages of the Philippines, not excluding the previous colonial languages of Spanish and English (Rappa and Wee 2006).

Tagalog, the language upon which Filipino is based, is the language with the largest numbers of speakers. There are several other major languages, including Cebuano, Ilocano, Hiligaynon, Bicol and Waray. As will be illustrated below in the section on language education, these and other languages are now used as languages of education in elementary (primary) schools. Unlike the situation in Indonesia, the choice of which language should be the national language was very much a top-down decision and it is therefore not surprising that the choice fell upon the language spoken in and around the capital, Manila. 
In Vietnam, the great majority of the 80 million population are first language speakers of Vietnamese. In addition to these first language speakers of Vietnamese, there are fifty-four ethnic groups with their own languages (Thaveeporn 2003). However, given that some 90 percent of the population are speakers of Vietnamese, the adoption otnamese as the national language seems natural. These choices are easi relatively homogeneous societies where the great majority share the same first language, as is the case, for example, in Japan and Korea. In China, however, the linguistic situation is more complex, as will be illustrated below.

As is well-known, China is the most populous nation on earth with a total population approaching 1.4 billion. It represents a further example of where the national language, Putonghua, has been decided by the government. Putonghua, which literally means 'common language', is based on the northern variety of Mandarin. The Chinese language can be divided, however, into seven dialect groups, many of which have many millions of speakers. Shanghainese (or Wu to give the language group its official name) has 77 million speakers and Cantonese (or Yue) has more than 56 million speakers (Ostler 2010: 227). The Min dialect group comprises Min Nan Hua (Southern Min, of which Hokien is a variety) and which is also the major dialect of Taiwan and spoken widely among the Chinese diaspora (Wei 2010). The Xiang, Hakka and Gan languages make up the seven major groupings. It is important to underline that the spoken forms of these dialects are mutually unintelligible.

The National Language Law of China proscribes the use of any of these Chinese languages other than the national language, Putonghua, as a language of education. This means, for example, that, by law, Cantonese cannot be taught in the schools of Guangdong Province. The only languages, other than 'foreign' languages such as English, which can be taught in the government school system are the languages of certain national minorities, such as Mongolian and Zhuang, and I return to this in the section under language education below.

The Chinese government's promotion of Putonghua as the national language has been an outstanding success in that the majority of Chinese now report being able to understand and use the language. There has also been a substantial increase in demand outside China for Putonghua. Partly to meet this demand, but more to promote Chinese and Chinese culture outside China, the Chinese government has, since 2004, established a number of Confucian Institutes. By 2010, 396 Confucian Institutes had already been established across eighty-seven countries (Ostler 2010: 245). The goal is for 1,000 Institutes by 2020 .

In this introduction, I have given a brief review of languages that are being used either as regional or national lingua francas in East and Southeast Asia. It is interesting to note that the reasons for the choices of the respective national lingua francas were different. In the case of Filipino and Putonghua, 
the language spoken in and around the respective capitals was chosen as the national lingua franca. In the case of Vietnam, the language spoken by the great majority of the people was chosen. And, in the case of Indonesia, a language spoken only by a very small minority of the people was chosen.

This is not, by any means, an exhaustive list. Many other languages act as national lingua francas, with Burmese and Khmer, the language of Cambodia, just two examples. In the next section, I examine in more detail the role of English as a lingua franca within the region, and consider the consequence of this for language education practices and policies.

\subsection{English as a lingua franca}

As noted above, English is the sole working language of ASEAN. This fact is particularly significant in that English is playing an official role in cultural contexts beyond its traditional native speaker Anglo-cultural sphere. It is true, of course, that this is not the first and only time for English to play that role. Many different varieties of English have developed across the world, giving rise, for example to new varieties of English across Africa and Asia. It is axiomatic that these new varieties of English have developed ways of referring to and reflecting the cultures of their speakers (Kachru 1983; Kirkpatrick 2007). There is nothing new or surprising in this. In the same way, for example, that Australian English has developed to reflect the cultures of Australians, so too have the various Englishes of Africa and Asia. A common way of indigenization is to adopt words from local languages to describe or refer to local phenomena. Thus, kangaroo, boomerang and koala are now words of Australian English, but remain also part of the lexis of (different) local Australian Aboriginal languages. Thus, kampong (village), makan (food/eat) and adat (traditional customs) are now words of Malaysian English, but remain part of the lexis of Malay. New varieties also express the cultural conceptualizations of their speakers. For example, specific kinship terms in varieties of African English represent the importance these cultures place on family ties (Wolf 2010). New varieties are also linguistically influenced by the first languages of their speakers. The extent of this influence is a matter of degree, but is seen in all varieties (Mufwene 2001). I shall not expound on the development of Asian varieties of World English in any detail here. Interested readers are referred to Bolton (2003), Kachru (2005), Kirkpatrick (2007) and Low and Azirah (2012). The point to be stressed here is that with its official adoption as the working language of this group of ten Asian countries, English has been voluntarily chosen by ASEAN members to act as the lingua franca where there are no native speakers, as traditionally defined, of the language. This role is moving English into a post-Anglo-cultural sphere and into an Asian sphere. As a minister in the Cambodian government reported some years ago, 'You know, when we 
use English, we don't think about the United States or England. We only think about the need to communicate' (Clayton 2006: 233).

In order to investigate what this use of English as a lingua franca across ASEAN entails, a group of researchers is collecting a corpus of English as used as a spoken lingua franca by Asian multilinguals. This is the Asian Corpus of English (ACE) which was released in $2014^{1}$. It may seem obvious to point out, but the topics that such Asian multilinguals discuss are topics which are relevant, important and interesting to them. The topics are centred in Asian cultural contexts (Kirkpatrick, Patkin and Jingjin $\Omega$ 13). These Asian multilinguals have taken ownership of English and, as will be explored in further detail below, this means that those visiting Asia need to become familiar with Asian varieties of English and how it is used in lingua franca contexts. The cultural frame of reference required is an Asian one not an Anglo-American one.

A noteworthy example of the use of English as a lingua franca in new fields and in cultural contexts that are firmly divorced from an Anglo-American influences is its use in the teaching of English for Islamic values in boarding schools attached to mosques in Indonesia. These schools are known as pesantren and have been teaching English for many years, although parents were concerned that the English being taught should be in accord with Islamic values (Fahrudin 2013). Fahrudin reports how the pesantren have managed the apparent conflicts between Islam and an English loaded with western cultural values and have successfully integrated Islamic perspectives. As a simple example, when children in the pesantren are taught the use of 'will' to indicate promises or plans, they attach the suffix 'insya' Allah' (or God willing) to give a sentence such as 'I will come tomorrow, insya'Allah'. Fahrudin also reports that some mosques in the Indonesian capital, Jakarta, now use English for the seven-minute talk which follows prayers, due to the increase in the number of foreigners attending these mosques.

\subsection{Implications for language(s) education}

The take up of English in East and Southeast Asia has, not surprisingly, been reflected in the schools' curricula throughout the region. Indonesia is the only country of ASEAN which does not make English a compulsory subject in primary school and the new curriculum, currently being trialed also drops it as a compulsory and discrete subject from the secondary school syllabus. All the other countries in the ASEAN group make English compulsory from primary school. At the opposite end of the English language continuum from Indonesia lies Singapore. Singapore has a bilingual policy that can be summarized as English + 1. It places the most importance upon English by making it the medium of instruction for all subjects from primary one. The ' +1 ' represents the so-called mother tongue, of which three are taught, namely Mandarin 
Chinese (known as hиауи in Singapore), Malay and Tamil. These 'mother tongues' are actually determined by ethnicity rather than language. Thus, all ethnically Chinese Singaporeans learn Mandarin as their mother tongue in school, no matter whether this is their first language or not. Not surprisingly given the bilingual policy, English is becoming the dominant home language of an increasing number of Singaporeans. This has meant that the government has had to rethink how to teach the mother tongues and to treat them more as foreign languages. English is now playing an increasing role in the teaching of these mother tongues (Silver and Bokhorst-Heng, 2013). The original idea behind the bilingual policy was for English to ensure that Singaporeans were able to participate in and contribute to globalization and modernization and for the mother tongue to keep them in touch with the cultural backgrounds. However, the development of Singapore English and in particular the informal colloquial variety of Singaporean English, Singlish, has, in my view, taken over both roles, those of modernization and local identity (Kirkpatrick 2010a).

Brunei has long implemented a bilingual (dwibahasa) policy with standard Malay and English being the two languages in question (Jones 2000), but with some variations in the roles each of the language has played. For example, until 2009, Malay was the medium of instruction until Primary 3, with English taking over as the medium of instruction (MoI) for a range of subjects including maths, science, geography, history and technical subjects from Primary 4, with Malay remaining the MoI for Malay literature, Islamic knowledge, civics, physical education and handicrafts. The adoption in 2011 of the National Education System for the twenty-first century introduced English as the MoI from Primary 1 for the teaching of maths and science. This move to introduce English as the MoI from Primary 1 represents the reverse of the new policy in Malaysia, which has abandoned the use of English as a MoI for maths and science from Primary 1, replacing it with Malay (Gill 2012). English remains a subject to be taught in Primary school. As Gill notes, the scrapping of the English-medium policy, which had been in force since 2002, was caused by a complex array of reasons including the results of research studies which showed that the policy disadvantaged students from rural and lower socioeconomic backgrounds, and the lack of proficiency in English of some students and teachers, especially for the teaching of maths and science through Gi 12 12: 45).

Another country in the ASEAN group to have recently revised its language education policies is the Philippines. Until the recent changes, English and the national language, Filipino, have been the two media of instruction in schools from Primary 1 (known as Grade 1 in the Philippines). For example, the revised Bilingual Education Policy (BEP) of 1987 made English the MoI for maths, science and English and Filipino the MoI for the other subjects. As reported above, Filipino is actually derived from Tagalog and Tagalog is 
traditionally restricted to the capital, Manila and the surrounding areas. The choice of Filipino as the national lingua franca and one of the two official mediums of instruction therefore meant that non-Tagalog speaking children could arrive in primary school to find they had to learn in two new languages. To simplify an extremely complex series of language policy debates, over the years there have been 'frequent efforts at incorporating vernacular languages into the curriculum...' (Dekker and Young 2005: 186), but it was not until the Education Department issued an order, Institutionalising Mother Tongue-based Multlilingual Education, in 2009 that the advantages of using the child's first language in education were officially endorsed. More recently, in May 2013, President Benigno Aquino signed into law the Enhanced Basic Education Act, extending compulsory education to thirteen years, comprising one year of kindergarten, six years of primary and six years secondary. Part of the act reads, 'For kindergarten and the first three years of elementary education, instruction, teaching materials and assessment shall be in the regional or native language of the learners'.

This seems a Herculean task, given, as mentioned above that 168 languages are used in the Philippines. In effect, languages with orthographies will be chosen and a list of twel Dijor languages which can be used as languages of education has been publisicd.

The Act also stipulates that Grades $4-6$ will be a transition period when English and Filipino gradually take over as $\mathrm{MoI}$ in preparation for secondary school. This has dissatisfied many of the proponents of Mother Tongue-based Multilingual Education (MTB-MLE), who are still calling for the local vernaculars to be used throughout primary school. In any event, it will probably be about another three to five years before the use of MTB-MLE can be properly evaluated (Nolasco, personal communication, May 30, 2013).

English plays a possibly unique role among the Filipino workforce, as proficiency in English allows so many Filipinos to work overseas. This overseas workforce remits part of its earnings home. The most recent figures from the National Statistics Office of the Philippines reported that, in 2011, over 2 million Filipinos were working overseas - with a roughly equal gender ratio. The homeward remittances of Filipino overseas workers in 2012 totaled more than US\$2 billion (National Statistics Office 2013). This opportunity to work overseas is crucially important, as the country suffers from chronic under-employment. One avenue for work at home is provided by the growing Call Centre Industry (Bolton 2010). This industry employed 300,000 workers in 2008 and this number had increased to 416,000 by 2011, with a projected additional 150,000 jobs to come as the industry moves beyond Metro Manila and into the so-called Next Wave Cities (Everest Group 2012). But, although this exemplifies 'the role of English as the language of modernity and development in Asia's dramatically developing economies' (Bolton 2010: 562), 
call centre English is very much connected with an Anglo-American cultural context, as the English used by call centre operatives is required to mimic American English. That this is resented by the operatives themselves is illustrated by the lyrics of the 'Call Centre Song', by the band, Cambio, 'Now let's get one thing straight, I don't really want to work this way, but I get paid for my American accent, I got money to pay the rent' (Bolton 2010: 559).

For the final example of national language education policy, I move beyond ASEAN and consider the situation in China. It is impossible to predict with any accuracy the number of people learning English in China, but English is a compulsory school subject from Grade 3 upwards. The Chinese Ministry of Education figures for 2008 show that there are about 71 million students in Grades 3-6, 85 million secondary school students and 10 million tertiary students (Qiufang 2012). As the overwhelming majority of these students are learning English, this means that there are some 160 million students learning English from primary through to undergraduate level. This does not take into account those school children learning English privately, students at postgraduate level or adults who are learning English for whatever reason. In any event, it seems safe to assume that Chinese learning English now outnumber the total number of native speakers of it. This development has given rise to some debate over whether a new Chinese variety of English has developed. Zhichang (2010), in describing a series of linguistic features presents a persuasive account that one can now indeed sensibly talk about a Chinese variety of English.

English currently enjoys a uniquely privileged position in China's language education policy, with more people learning the language than learn Chinese languages, other than Putonghua itself. As indicated above, The National Language Law prescribes Putonghua as the sole Chinese language of education, going as far as to proscribe the teaching of other Chinese languages. The government does allow the teaching of national minority languages (such as Mongolian, Korean and Zhuang), but the success of these bilingual (or trilingual if one includes English) policies is limited (Feng and Adamson, in pre

One area where English has made significant inroads is in higher edueation -and this also is true in many other Asian countries (Kirkpatrick 2013) - but here the focus will be on China and Hong Kong. As long ago as 2001, the then Chinese Premier, Zhu Rongji, announced while on a visit to the School of Economics and Management at the prestigious Tsinghua University: 'I hope that all classes will be taught in English. I don't worship foreign languages, but we need to exchange our ideas with the rest of the world'.

China's University and College Admissions System (CUCAS) provides a link to degree programmes taught in English under the tab 'Quick access to hot majors in English'. These include a wide range of undergraduate degrees in Medicine and Dentistry, Economics and Management, Law, Engineering 
(eight branches), Biology and Journalism. A range of Masters and Doctoral programmes available in English are also listed.

In Hong Kong, six of the eight government-funded universities are English medium. Even the Chinese University of Hong Kong, which was established in 1963 to provide Chinese medium courses, has recently moved to increase the number of English medium courses that it offers with the explicitly stated goal of increasing its international profile (Li 2013). This move caused great controversy among the student body, with one student filing an application for judicial review, arguing that the university's charter stipulated that Chinese be the major medium of instruction at the university. This application was rejected by the Court of Final Appeal in 2011, stating that the university had the right to mandate the medium of instruction ( $\mathrm{Li} 2013: 74)$. As Li (2013: 81) points out, there is strong evidence that English has been embraced as a form of linguistic capital, crucial for Hong Kong's continued economic vitality and development.

This is particularly striking in the case of China and Hong Kong, where the linguistic capital of Putonghua would appear to be undervalued. While, as reported above, the Chinese government has moved to establish hundreds of Confucian Institutes throughout the world, and while many Chinese universities offer non-degree programmes in Chinese language, most universities in China and Hong seem curiously hesitant about offering bilingual degrees that would see students graduate bilingual and biliterate in Chinese and English. One would expect degrees that graduated students bilingual and biliterate in these two languages would be in high demand.

The shift to providing English medium degree courses is, of course, not simply an Asian phenomenon, but is a world-wide trend (Doiz, Lasagabaster and Sierra 2013, Jenkins 2014), and would be very familiar to European universities. Reasons are complex and often financially driven (Knight 2008), but a desire to climb the university rankings is commonly evident. Internationalization is a key criterion used in measuring performance in university tables, and, as this almost always leads to universities adopting more EMI courses in order to attract international students and staff, internationalization can be equated to some extent with Englishization. This role of English in the rapidly increasing internationalization of higher education is as evident in Asia as anywhere else, if not more so.

Ti te, I have given an account of some of the roles of English in selected countries in East and Southeast Asia, along with a discussion of the consequences of these upon language education policies and practices. In the concluding section of the chapter, I shall consider the implications of these increasing and diverse roles of English in Asia's habitats for those needing to communicate with Asia. I shall start with a brief review of the Australian Government's recent White Paper, Australia in the Asian Century, as this itemizes the skills it believes Australians need to navigate what it calls the Asian 
Century. I shall then offer some thoughts on what skills I believe are needed to successfully engage with Asia in the coming years. This will include an account of 'Communicacy' (Kirkpatrick and Sussex 2012

\subsection{Communicating with Asia}

In October 2012, the Australian Government released a White Paper entitled Australia in the Asian Century (Commonwealth of Australia 2012). The government itself describes the document as a 'roadmap to guide Australia to becoming a more prosperous and resilient nation, fully part of the region and open to the world'. It is important to note that Australian governments have long promoted the study of Asian languages, but with limited success (Rudd 1994; Leitner 2007).

The importance of Asia to Australia is illustrated by these excerpts from the recent White Paper (Commonwealth of Australia 2012: 2): 'As a nation we also need to broaden and deepen our understanding of Asian cultures and languages, to become more Asia literate'. In order to help Australians become 'Asia literate', the White Paper (2012: 15) promises that 'Every Australian student will have significant exposure to studies of Asia across the curriculum...' and that 'All schools will engage with at least one school in Asia to support the teaching of a priority Asian language' (i.e., Mandarin, Hindi, Japanese and Indonesian). Although the White Paper is short on detail on how these policies might be implemented, it clearly underscores the increasing importance of Asia. And while few could argue with the need for more Australians to become Asia literate and to learn Asian languages, there is no acknowledgment in the White Paper of the new roles English is playing in the region and how an understanding of these might help Australians successfully engage with Asian multilinguals. This represents a missed opportunity, for although learning an Asian language in depth is the best way to communicate and work with Asia, it takes perseverance and commitment to reach the required proficiency to be able to operate at advanced levels. Simultaneously, it is unlikely that any one individual will be able to reach the required levels of proficiency in several Asian languages. Therefore, while individuals should certainly be encouraged to develop these high levels of linguistic proficiency, courses in intercultural communication using English as a lingua franca could be an effective way of increasing Asian literacy among a greater number of people.

A danger in referring to 'Asia', as in 'The Asian Century', is that it may lead people to view Asia as a homogenous whole with a common unified purpose, when in fact it is characterized by great diversity and differences in opinion. One component such a course would need to include would therefore be to highlight the diversity within Asia, and an introduction to the different varieties 
of English which operate in Asia would promote the notion that variation is both natural and widespread. This would not need to be a detailed course which discussed in any depth the complete array of linguistic features distinctive to a particular variety. Rather, it should give students an exposure to these different varieties so that they become familiar with them. 'Familiar' needs to be interpreted in two ways here. First, students should become familiar with these varieties in that they become aware of their existence; second they should become familiar with these varieties so that they have experience in listening to people using these varieties. Any variety of English is more comprehensive to people who have had active exposure to it (Smith and Bisazza 1982: 269). This component should also educate native speakers of English that their way of speaking is no longer the only right way, and that the development of so many different varieties of English means that many different 'standard' Englishes are now being spoken by educated Asians. Not only this, native speakers of English need to be made aware that their variety of English may be internationally difficult to understand. Research over several decades has shown that certain traditional native speaker varieties of English are less internationally comprehensible than are newer varieties. For example, research which tested the mutual intelligibility of native and non-native speakers of English from a wide variety of origins concluded that 'the native speaker was always found to be among the least intelligible speakers' (Smith and Rafiqzad 1979: 395). Research into the comparative intelligibility of Australian, Hong Kong and Singaporean Englishes found that Australian English was the least intelligible to an international audience, and that Hong Kong English was the most intelligible (Kirkpatrick, Deterding and Wong 2008). These may be uncomfortable truths for native speakers, but it is essential that a course in intercultural communication establishes that international intelligibility does not correlate with being a native speaker.

The course needs also to expose students to the way Asian multilinguals use English as a lingua franca. For example, an understanding of the strategies that English as a lingua franca users adopt to ensure smooth communication can, in itself be very useful. Research has indicated that, generally speaking, speakers contrive to maintain collegiality and will cooperate to ensure successful outcomes (Knapp and Meierkord 2002). This phenomenon may be influenced by the so-called ASEAN way, itself based on two Malay concepts of musyawarah (dialogue) and muafakat (consensus) (Curley and Thomas 2007: 9). It can also be seen in the ways formal seminars are managed in Indonesia, where speaking turns are indicated by the Chair or Moderator of the session, which means that turn-stealing is rare and that people seldom talk over each other (Rusdi 1999; Kirkpatrick 2010). Participants know when it is their turn to speak. In more informal conversational settings both speakers and listeners adopt a range of communicative 
strategies, either to help listeners understand the message or to help speakers get their messages across. In a study of the communicative strategies of ASEAN speakers using ACE as data, ten listener strategies and five speaker strategies were identified. Listener strategies included lexical anticipation and suggestion, requesting repetition and clarification and participant paraphrase, whereby one of the listeners might rephrase what the speaker is saying in order to help one of the participants understand the message. Speaker strategies included being explicit, using paraphrase, and avoiding colloquial or idiomatic expressions (see Kirkpatrick 2010: 123ff for a full discussion). Indeed, it is striking that, although, by definition, the participants are Asian multilinguals, they seldom use words from their first language when engaged in lingua franca communication. This represents a striking contrast to when they are using their local variety of English with each other, as code-mixing is characteristic of such usage (Kirkpatrick and McLellan 2012). Interestingly, this also contrasts to findings from the European VOICE corpus, a corpus of primarily of Europeans using English as a lingua franca, where code-switching and idiomatic usage is more commonly found. The reason may be that many European languages are related, so that lingua franca users can be expected to be familiar with certain words from different languages.

In stressing the diversity within Asia, a course in intercultural communication in the use of English as an Asian lingua franca will also need to include an introduction to Asian cultures and pragmatic norms. The course could not aim to include in-depth information about each Asian culture, but would aim to develop intercultural competence in the students (Ting-Toomey and Chung 2005). As the brief account of a selection of the topics discussed in ACE illustrated, the great majority of discussion is centred around Asia, Asian events and Asian cultures. The course should also include an introduction to cultural conceptualizations, as these show how the culture of the speaker is reflected in the variety of English. For example, Sharifian describes key cultural conceptualizations as reflected in Persian English (Sharifian 2010) and Wolf shows how varieties of West and East African Englishes share cultural values (Wolf 2010). The chapter by Wolf and Chan (this volume) is relevant to this point.

\subsection{Conclusion}

In this chapter, I have outlined the burgeoning roles of the use of English as a lingua franca across East and Southeast Asia, illustrating these with specific examples. I have then considered the implications of the increasing roles of English for regional language education polices, again illustrating these with specific examples from across the region. In the final section of the chapter, I considered the implications of the roles of English in Asia for those wishing 
to communicate successfully with Asia and provided some suggestions for components for a course designed to help in this.

\section{NOTES}

1 ACE (corpus.ied.edu.hk/ace/) has been collected by teams across eight countries in Southeast Asia. The corpus comprises the naturally occurring speech of Asian multilinguals using English as a lingua franca. It will be complementary to the Vienna Oxford International Corpus of English (VOICE), which is a corpus of lingua franca English whose speakers are primarily, but not exclusively, multilingual Europeans. 